\title{
Stratification of brachytherapy-treated intermediate-risk prostate cancer patients into favorable and unfavorable cohorts
}

\author{
Gregory S. Merrick, MD',2, Wayne M. Butler, PhD', Robert W. Galbreath, PhD',3, Ryan Fiano, BS, MPH', \\ Edward Adamovich, MD4 \\ ISchiffler Cancer Center, Wheeling Jesuit University, Wheeling, WV, ${ }^{2}$ Department of Urology. Wheeling Hospital, Wheeling, WV \\ ${ }^{3}$ Ohio University, Eastern St. Clairsville, OH, ${ }^{4}$ Department of Pathology, Wheeling Hospital, Wheeling, WV. USA
}

\begin{abstract}
Purpose: To evaluate biochemical failure (BF) and prostate cancer specific mortality (PCSM) in intermediate-risk (IR) brachytherapy patients stratified into favorable and unfavorable cohorts, and to compare those outcomes to patients with low (LR) and high-risk (HR) disease.

Material and methods: From March 1995 till February 2012, 2,502 consecutive patients underwent permanent interstitial brachytherapy for clinically localized prostate cancer. Patients were stratified into risk groups as per the NCCN guidelines with further stratification of the intermediate risk cohort into unfavorable (primary Gleason pattern $4, \geq 50 \%$ positive biopsies or $\geq 2$ IR features) and favorable cohorts. Median follow-up was 8.5 years. The brachytherapy prescription dose was prescribed to the prostate gland with generous periprostatic margins. Biochemical failure was defined as a PSA $>0.40 \mathrm{ng} / \mathrm{ml}$ after nadir. Patients with metastatic prostate cancer or non-metastatic castrate resistant disease who died of any cause were classified as dead of prostate cancer. Multiple parameters were evaluated for effect on outcomes.

Results: Fifteen year BF for LR, favorable IR, unfavorable IR, and HR were 1.4\%, 2.2\%, 7.1\%, and 11.1\% $(p<0.001)$, respectively. At 15 years, PCSM for LR, favorable IR, unfavorable IR, and HR was $0.3 \%, 0.6 \%, 2.2 \%$ and $4.6 \%(p<0.001)$, respectively. In multivariate analysis, BF was best predicted by risk group, pre-implant PSA, percent positive biopsies, prostate volume, and ADT duration, while PCSM was most closely related to risk group, percent positive biopsies and prostate volume.

Conclusions: Patients with favorable IR disease have biochemical and PCSM outcomes comparable to those of patients with LR disease. Although unfavorable IR has greater than a 3-fold increased risk of BF and PCSM when compared to favorable IR, the outcomes remain superior to those men with HR disease.
\end{abstract}

J Contemp Brachytherapy 2015; 7, 6: 430-436 DOI: $10.5114 /$ jcb.2015.56763

Key words: biochemical outcome, brachytherapy, intermediate-risk, prostate cancer.

\section{Purpose}

Permanent interstitial brachytherapy is a highly efficacious treatment modality for patients with low, intermediate, and high-risk disease [1]. Intermediate-risk (IR) prostate cancer has been defined by the National Comprehensive Cancer Network (NCCN) as "T2b or T2c, Gleason score $\leq 7$ or PSA $10-20 \mathrm{ng} / \mathrm{ml}^{\prime \prime}$ [2]. However, because of substantially different risks of extracapsular extension and seminal vesicle and/or pelvic lymph node involvement among the IR cohort [3], the prognosis of IR patients can vary dramatically. In addition, the NCCN risk group stratification does not account for additional adverse prognosticators including multiple IR factors [4], fewer diagnostic biopsy cores [5], and more than $50 \%$ of the biopsies positive [6,7], which can result in prostate specific antigen (PSA) recurrence rates and prostate cancer specific mortality (PCSM) consistent with high-risk disease. Recently, Zumteg and colleagues stratified IR patients into favorable and unfavorable categories with the conclusion that unfavorable IR (primary Gleason pattern 4, $\geq 50 \%$ positive biopsies or $\geq 2$ intermediate-risk features) resulted in an increased risk of biochemical failure (BF), PCSM, and distant metastases (DM) when compared to favorable IR prostate cancer patients who were treated with dose-escalated intensity modulated external beam radiation therapy (IMRT) with or without 6 months of androgen deprivation therapy (ADT) [8]
Address for correspondence: Gregory S. Merrick, MD, Schiffler Cancer Center, Wheeling Hospital, 1 Medical Park, Wheeling, WV 26003, USA, phone: +1 304-243-3490, fax: +1 304-243-5047, e-mail: gmerrick@urologicresearchinstitute.org
Received: 27.10.2015

Accepted: 18.12 .2015

Published: 30.12 .2015 
Table 1. Clinical, treatment, and dosimetric parameters of low, intermediate, and high risk patients

\begin{tabular}{|c|c|c|c|c|c|c|c|c|c|c|c|}
\hline \multirow[t]{2}{*}{ Continuous variables } & \multicolumn{2}{|c|}{$\begin{array}{l}\text { Low risk } \\
(n=851)\end{array}$} & \multicolumn{2}{|c|}{$\begin{array}{l}\text { Favorable } \\
\text { intermediate risk } \\
(n=460)\end{array}$} & \multicolumn{2}{|c|}{$\begin{array}{l}\text { Unfavorable } \\
\text { intermediate risk } \\
\quad(n=780)\end{array}$} & \multicolumn{2}{|c|}{$\begin{array}{l}\text { High risk } \\
(n=411)\end{array}$} & \multirow[t]{2}{*}{$p^{*}$} & \multicolumn{2}{|c|}{$\begin{array}{c}\text { Total } \\
(n=2502)\end{array}$} \\
\hline & Median & Mean & Median & Mean & Median & Mean & Median & Mean & & Median & Mean \\
\hline Age at implant (yrs) & 64.0 & 63.1 & 65.0 & 64.6 & 66.0 & 65.6 & 67.0 & 66.5 & $<0.001$ & 65.0 & 64.7 \\
\hline Follow-up (yrs) & 8.5 & 8.9 & 8.0 & 8.4 & 8.6 & 8.8 & 7.7 & 8.2 & 0.006 & 8.5 & 8.7 \\
\hline PSA & 5.4 & 5.6 & 5.1 & 7.0 & 6.7 & 7.6 & 9.0 & 13.3 & $<0.001$ & 6.1 & 7.7 \\
\hline Prostate volume $\left(\mathrm{cm}^{2}\right)$ & 33.4 & 34.1 & 32.5 & 33.1 & 30.4 & 30.6 & 25.4 & 27.5 & $<0.001$ & 31.2 & 31.7 \\
\hline Gleason score & 6.0 & 5.9 & 7.0 & 6.8 & 7.0 & 7.0 & 8.0 & 8.2 & $<0.001$ & 7.0 & 6.8 \\
\hline Percent positive biopsies & 16.7 & 23.8 & 25.0 & 24.0 & 50.0 & 51.0 & 50.0 & 52.5 & $<0.001$ & 33.3 & 37.0 \\
\hline BMI & 27.7 & 28.2 & 27.6 & 28.2 & 27.9 & 28.8 & 28.1 & 29.0 & 0.007 & 27.9 & 28.5 \\
\hline$\% D_{90}$ & 118.3 & 117.9 & 118.5 & 118.8 & 120.8 & 120.5 & 122.2 & 121.5 & $<0.001$ & 119.6 & 119.5 \\
\hline$V_{100}$ & 97.8 & 96.5 & 97.8 & 96.8 & 98.2 & 96.9 & 98.3 & 97.1 & 0.065 & 98.0 & 96.8 \\
\hline$V_{150}$ & 69.6 & 67.0 & 71.0 & 68.6 & 72.5 & 69.8 & 73.8 & 70.9 & $<0.001$ & 71.2 & 68.8 \\
\hline$V_{200}$ & 39.1 & 37.3 & 40.8 & 39.3 & 42.5 & 40.9 & 43.9 & 42.2 & $<0.001$ & 41.2 & 39.6 \\
\hline Last PSA & $<0.02$ & 0.02 & $<0.02$ & 0.04 & $<0.02$ & 0.03 & $<0.02$ & 0.02 & 0.014 & $<0.02$ & 0.03 \\
\hline Categorical variables & Count & (\%) & Count & $(\%)$ & Count & (\%) & Count & (\%) & $p^{*}$ & Count & (\%) \\
\hline \multicolumn{12}{|l|}{ PSA: } \\
\hline$\leq 10 \mathrm{mg} / \mathrm{dl}$ & 851 & (100) & 387 & $(84.1)$ & 599 & $(76.8)$ & 226 & (55.0) & \multirow[t]{2}{*}{$<0.001$} & 2063 & $(82.5)$ \\
\hline$>10$ mg/dl & 0 & (0) & 73 & $(15.9)$ & 181 & $(23.2)$ & 185 & $(45.0)$ & & 439 & (17.5) \\
\hline \multicolumn{12}{|l|}{ Gleason score: } \\
\hline$\leq 6$ & 851 & (100) & 92 & (20.0) & 36 & $(4.6)$ & 20 & $(4.9)$ & \multirow[t]{4}{*}{$<0.001$} & 999 & (39.9) \\
\hline $7(3+4)$ & 0 & (0) & 368 & $(80.0)$ & 314 & $(40.3)$ & 12 & $(2.9)$ & & 694 & $(27.7)$ \\
\hline $7(4+3)$ & 0 & (0) & 0 & (0) & 430 & $(55.1)$ & 33 & (8.0) & & 463 & $(18.5)$ \\
\hline$\geq 8$ & 0 & (0) & 0 & (0) & 0 & (0) & 346 & $(84.2)$ & & 346 & (13.8) \\
\hline \multicolumn{12}{|l|}{ Stage: } \\
\hline$\leq \mathrm{T} 2 \mathrm{a}$ & 851 & $(100)$ & 444 & $(96.5)$ & 636 & $(81.5)$ & 288 & $(70.1)$ & \multirow[t]{4}{*}{$<0.001$} & 2219 & $(88.7)$ \\
\hline $\mathrm{T} 2 \mathrm{~b}$ & 0 & (0) & 10 & $(2.2)$ & 97 & (12.4) & 63 & (15.3) & & 170 & (6.8) \\
\hline $\mathrm{T} 2 \mathrm{c}$ & 0 & (0) & 6 & $(1.3)$ & 47 & (6.0) & 45 & $(10.9)$ & & 98 & (3.9) \\
\hline T3a-c & 0 & (0) & 0 & (0) & 0 & (0) & 15 & (3.6) & & 15 & $(0.6)$ \\
\hline \multicolumn{12}{|l|}{ EBRT: } \\
\hline O Gy & 830 & $(97.5)$ & 204 & $(44.3)$ & 168 & $(21.5)$ & 16 & (3.9) & \multirow[t]{3}{*}{$<0.001$} & 1218 & $(48.7)$ \\
\hline 20 Gy & 3 & $(0.4)$ & 146 & $(31.7)$ & 176 & $(22.6)$ & 29 & (7.1) & & 354 & $(14.1)$ \\
\hline 44-50.4 Gy & 18 & (2.1) & 110 & (23.9) & 436 & (55.9) & 366 & (89.1) & & 930 & $(37.2)$ \\
\hline \multicolumn{12}{|l|}{ ADT: } \\
\hline None & 655 & (77.0) & 368 & (80.0) & 562 & $(72.1)$ & 116 & $(28.2)$ & \multirow[t]{3}{*}{$<0.001$} & 1701 & $(68.0)$ \\
\hline$\leq 6$ months & 188 & $(22.1)$ & 85 & $(18.5)$ & 123 & $(15.8)$ & 52 & $(12.7)$ & & 448 & (17.9) \\
\hline$>6$ months & 7 & $(0.9)$ & 7 & $(1.5)$ & 95 & $(12.2)$ & 243 & $(59.1)$ & & 353 & $(14.1)$ \\
\hline \multicolumn{12}{|l|}{ Hypertension: } \\
\hline No & 439 & (51.6) & 227 & (49.3) & 374 & $(47.9)$ & 185 & (45.0) & \multirow[t]{2}{*}{0.154} & 1225 & (49.0) \\
\hline Yes & 412 & $(48.4)$ & 233 & $(50.7)$ & 406 & $(52.1)$ & 226 & $(55.0)$ & & 1277 & (51.0) \\
\hline \multicolumn{12}{|l|}{ Diabetes: } \\
\hline No & 766 & (90.0) & 400 & (87.0) & 679 & $(87.1)$ & 355 & (86.4) & \multirow[t]{2}{*}{0.145} & 2200 & $(87.9)$ \\
\hline Yes & 85 & $(10.0)$ & 60 & $(13.0)$ & 101 & $(12.9)$ & 56 & (13.6) & & 302 & $(12.1)$ \\
\hline Hypercholesterolemia: & & & & & & & & & & & \\
\hline No & 553 & $(65.0)$ & 291 & $(63.3)$ & 504 & $(64.6)$ & 271 & $(65.9)$ & 0.867 & 1619 & $(64.7)$ \\
\hline Yes & 298 & (35.0) & 169 & $(36.7)$ & 276 & $(35.4)$ & 140 & (34.1) & & 883 & $(35.3)$ \\
\hline
\end{tabular}


Table 1. Cont.

\begin{tabular}{|c|c|c|c|c|c|c|c|c|c|c|c|}
\hline Categorical variables & Count & (\%) & Count & (\%) & Count & (\%) & Count & (\%) & $p^{*}$ & Count & (\%) \\
\hline \multicolumn{12}{|l|}{ Cardiovascular disease: } \\
\hline No & 733 & $(86.1)$ & 378 & $(82.2)$ & 646 & $(82.8)$ & 326 & $(79.3)$ & \multirow[t]{2}{*}{0.018} & 2083 & $(83.3)$ \\
\hline Yes & 118 & (13.9) & 82 & $(17.8)$ & 134 & (172.) & 85 & $(20.7)$ & & 419 & $(16.7)$ \\
\hline \multicolumn{12}{|l|}{ Tobacco: } \\
\hline Never & 382 & $(44.9)$ & 187 & $(40.7)$ & 282 & $(36.2)$ & 145 & $(35.5)$ & \multirow[t]{3}{*}{0.006} & 996 & $(39.9)$ \\
\hline Former & 346 & $(40.7)$ & 195 & $(42.4)$ & 356 & $(45.7)$ & 196 & $(48.0)$ & & 1093 & $(43.8)$ \\
\hline Current & 122 & $(14.4)$ & 78 & $(17.0)$ & 141 & $(18.1)$ & 67 & $(16.4)$ & & 408 & $(16.3)$ \\
\hline \multicolumn{12}{|l|}{ Testosteronet: } \\
\hline Low/low $1 / 3$ norm & 399 & $(68.6)$ & 236 & $(72.0)$ & 343 & $(67.1)$ & 182 & $(66.9)$ & \multirow[t]{3}{*}{0.377} & 1160 & $(68.5)$ \\
\hline Middle $1 / 3$ norm & 147 & $(25.3)$ & 65 & $(19.8)$ & 123 & $(24.1)$ & 68 & $(25.0)$ & & 403 & (23.8) \\
\hline Upper $1 / 3$ norm/high & 36 & $(6.2)$ & 27 & $(8.2)$ & 45 & (8.8) & 22 & $(8.1)$ & & 130 & (7.7) \\
\hline
\end{tabular}

${ }^{t}$ Only 1,693 patients had testosterone values

*Significance for continuous data was determined using a one-way ANOVA and $\chi^{2}$ or Fisher's exact test for categorical data

Using the Zumteg and Spratt classification system for IR disease, increased failure rates in men with unfavorable IR have been reported following both IMRT and radical prostatectomy $[9,10]$. In addition, recently our group reported the results of a prospective randomized trial evaluating the role of supplemental external beam radiation therapy in patients with higher risk features [11]. A subsequent post-hoc evaluation of that study subdividing IR into favorable and unfavorable cohorts concluded that unfavorable IR resulted in a greater rate of biochemical failure but no overall difference in PCSM or overall mortality [12]. In the current study, we evaluate the impact IR stratification into favorable and unfavorable cohorts in a large series of non-selected permanent prostate brachytherapy patients.

\section{Material and methods}

From March 1995 till February 2012, 2,502 consecutive patients underwent permanent interstitial brachytherapy for clinically localized prostate cancer by a single brachytherapist (GSM). All patients were treated more than 3 years prior to analysis. All pathology was reviewed by a single pathologist (EA) to minimize inconsistencies in Gleason grading. Risk group stratification was as per the NCCN risk group recommendations [2]. Patients were clinically staged using medical history and physical examination including digital rectal examination (DRE) and serum PSA. Bone scan and computed tomography (CT) of the abdomen/pelvis were obtained at the discretion of either the referring or treating physician.

Pre-planning technique, intraoperative approach, and dosimetric evaluation have previously been described in detail $[13,14]$. The brachytherapy target volume consisted of the prostate gland with a $5 \mathrm{~mm}$ periprostatic margins and the proximal $1.0 \mathrm{~cm}$ of the seminal vesicles with a resultant planning target volume of approximately 1.9 times the actual prostate volume $[13,14,15]$. All post-implant dosimetric calculations were based on day 0 evaluation.

When utilized, supplemental external beam radiation therapy (EBRT) was delivered prior to brachytherapy.
For patients with a pelvic lymph node risk $\geq 10 \%$ [3], the pelvic lymph nodes were included within the target volume. For all others the prostate gland/seminal vesicles were irradiated with margin. When employed, supplemental EBRT was generally administered at a dose of 45-50.4 Gy. However, 354 patients did receive 20 Gy of supplemental EBRT delivered to the prostate gland and seminal vesicles with margin. When utilized, ADT was initiated 3 month prior to implantation and consisted of either a leutinizing hormone releasing hormone (LHRH) antagonist or agonist with or without an anti-androgen. The median and mean duration of ADT was 4 months and 9 months (range 3-36 months). Indications for ADT were prostate cytoreduction and/or adverse pathologic prognosticators.

Following brachytherapy, patients were monitored by physical examination including DRE and PSA determinations at 3 and 6 month intervals. The end-point of the analysis was BF, PCSM, and overall mortality (OM). Biochemical failure was defined as a PSA $>0.40 \mathrm{ng} / \mathrm{ml}$ after nadir. This definition has been shown to be particularly sensitive in detecting treatment failure [16]. Patients who failed to achieve a nadir $\leq 0.40 \mathrm{ng} / \mathrm{ml}$ were categorized as biochemical failures. The cause of death was determined for each deceased patient. Patients with metastatic prostate cancer or non-metastatic castrate resistant disease who died of any cause were classified as dead of prostate cancer. All other deaths were attributable to the immediate cause of death. Multiple clinical, treatment, and dosimetric parameters were evaluated for effect on survival.

Clinical and treatment variables that were continuous were compared across groups using a one-way analysis of variance (ANOVA). Categorical variables were compared using a chi-square analysis. Biochemical failure, PCSM, and $\mathrm{OM}$ were determined using cumulative incidence and cumulative survival curves. Competing risk analysis was used to compare BF with the population stratified by low, favorable-intermediate, unfavorable-intermediate, and high-risk all competing risk analyses used STATA version 13.0 software (StataCorp, College Station, TX, 


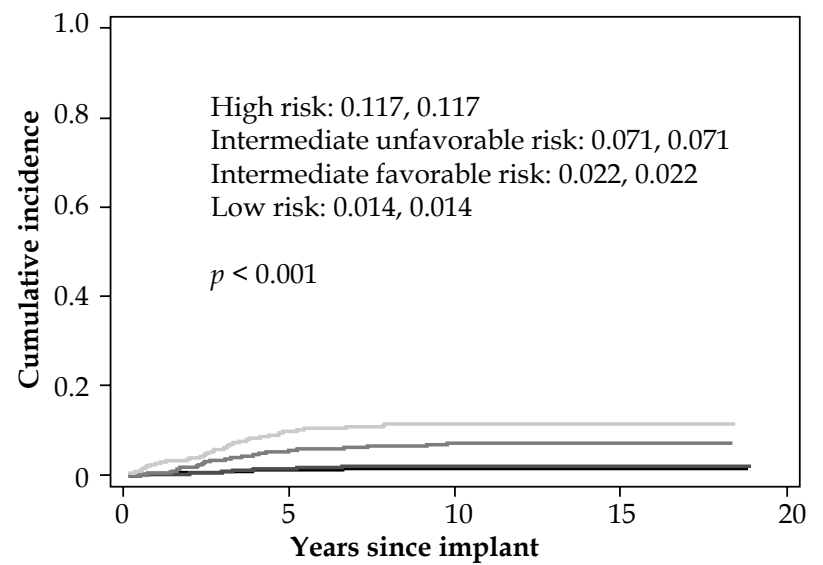

Fig. 1. Biochemical failure, stratified by NCCN risk (cumulative incidence presented at year 10 and 15)

USA), while $\chi^{2}$ and ANOVA tests were formed using either STATA or Social Sciences, version 18.0 (SPSS, Inc. Chicago, IL, USA).

\section{Results}

Table 1 summarizes the clinical, treatment, and dosimetric parameters of the low, intermediate (stratified into favorable and unfavorable cohorts), and high-risk patients comprising this study. As per NCCN classification, higher risk patients presented with higher Gleason scores, higher PSA, and higher clinical T-stage. In addition, higher risk patients tended to be statistically older with a smaller prostate volume, a higher incidence of percent positive biopsies, were more likely to receive supplemental EBRT and ADT. In addition, high-risk patients had a statistically shorter follow-up but the difference in mean follow-up between the 4 evaluated cohorts was 0.7 years or less. For the entire cohort, the mean day 0 $V_{100}$ and $D_{90}$ were $96.8 \%$ and $119.5 \%$, respectively. For biochemically controlled patients, the most recent PSA was $<0.02 \mathrm{ng} / \mathrm{ml}$.

Figure 1 illustrates biochemical failure when stratified by the four risk group categories. The 15 year rate of biochemical failure for patients with low risk (LR), favorable

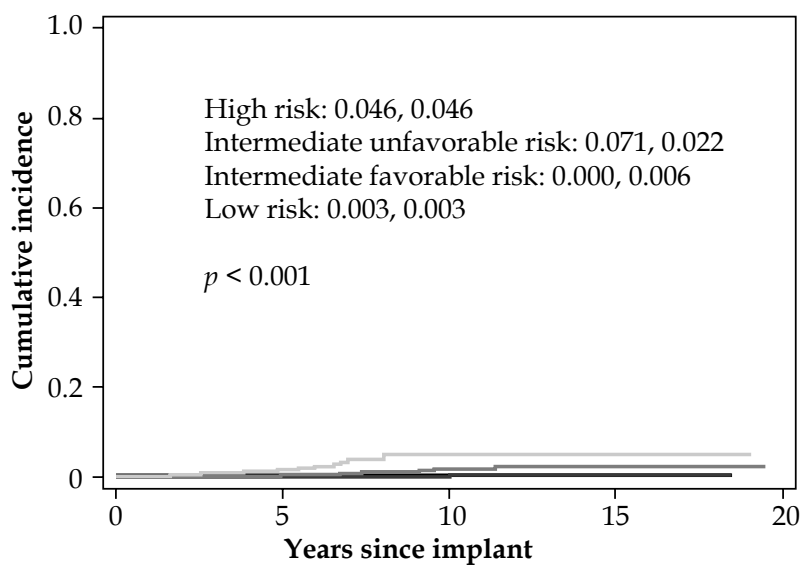

Fig. 2. Prostate-specific mortality, stratified by NCCN risk (cumulative incidence presented at year 10 and 15)

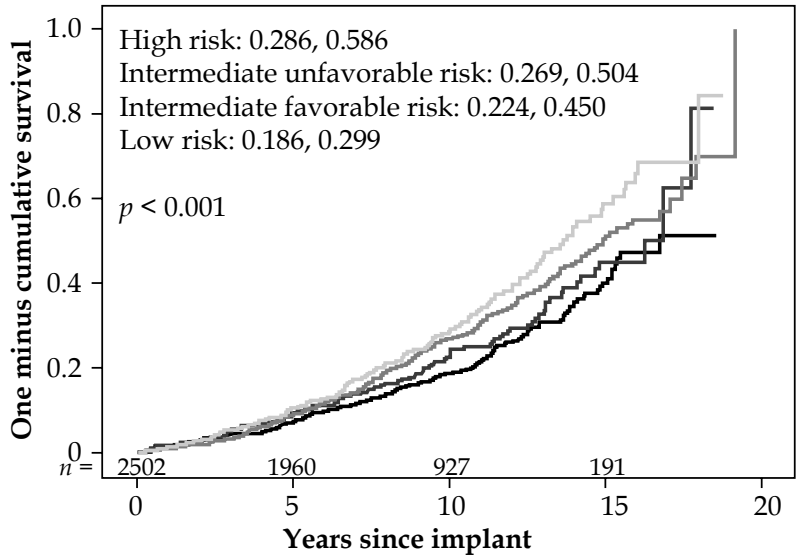

Fig. 3. Overall mortality, stratified by NCCN risk (one minus cumulative survival presented at years 10 and 15)

IR, unfavorable IR, and high-risk (HR) was $1.4 \%, 2.2 \%$, $7.1 \%$, and $11.7 \%$, respectively ( $p<0.001$ ). Figure 2 stratifies the same four risk groups by PCSM. At 15 years, the PCSM for LR, favorable IR, unfavorable IR, and HR was $0.3 \%, 0.6 \%, 2.2 \%$, and $4.6 \%$, respectively $(p<0.001)$. Overall 15 year mortality for LR, favorable IR, unfavorable IR,

Table 2. Distribution of cause of death, stratified by risk

\begin{tabular}{|c|c|c|c|c|c|c|c|c|c|c|}
\hline \multirow[t]{2}{*}{ Continuous variables } & \multicolumn{2}{|c|}{$\begin{array}{l}\text { Low risk } \\
(n=185)\end{array}$} & \multicolumn{2}{|c|}{$\begin{array}{c}\text { Favorable } \\
\text { intermediate risk } \\
(n=107)\end{array}$} & \multicolumn{2}{|c|}{$\begin{array}{c}\text { Unfavorable } \\
\text { intermediate risk } \\
(n=232)\end{array}$} & \multicolumn{2}{|c|}{$\begin{array}{l}\text { High risk } \\
(n=130)\end{array}$} & \multicolumn{2}{|c|}{$\begin{array}{c}\text { Total } \\
(n=654)\end{array}$} \\
\hline & Count & Percent & Count & Percent & Count & Percent & Count & Percent & Count & Percent \\
\hline Prostate cancer & 2 & $(1.1)$ & 1 & (0.9) & 9 & (3.9) & 13 & $(10.0)$ & 25 & (3.8) \\
\hline Bladder cancer & 3 & (1.6) & 3 & $(2.8)$ & 0 & $(0.0)$ & 2 & $(1.5)$ & 8 & $(1.2)$ \\
\hline Colon cancer & 7 & (3.8) & 7 & $(6.5)$ & 3 & (1.3) & 6 & $(4.6)$ & 23 & (3.5) \\
\hline Lung cancer & 22 & (11.9) & 12 & $(11.2)$ & 30 & $(12.9)$ & 18 & $(13.8)$ & 82 & $(12.5)$ \\
\hline Other cancers & 28 & $(15.1)$ & 27 & $(25.2)$ & 34 & $(14.7)$ & 14 & $(10.8)$ & 103 & $(15.7)$ \\
\hline Cardiovascular disease & 71 & $(38.4)$ & 32 & $(29.9)$ & 93 & $(40.1)$ & 54 & $(41.5)$ & 250 & $(38.2)$ \\
\hline Pulmonary disease & 21 & $(11.4)$ & 13 & $(12.1)$ & 21 & (9.1) & 12 & $(9.2)$ & 67 & $(10.2)$ \\
\hline Alzheimer's disease & 10 & (5.4) & 6 & (5.6) & 7 & (3.0) & 3 & (2.3) & 26 & $(4.0)$ \\
\hline Other & 22 & (11.9) & 12 & (11.2) & 30 & $(12.9)$ & 18 & (13.8) & 82 & (12.5) \\
\hline
\end{tabular}


and high-risk was $29.9 \%, 45.0 \%, 50.4 \%$, and $58.6 \%$, respectively $(p<0.001)$ (Figure 3).

Table 2 stratifies causes of death by risk group. Overall, 654 patients have died with cardiovascular disease (250 patients, 38.2\% of all deaths) representing the most common cause of death. Twenty-five (3.8\% of all deaths) were attributable to castrate resistant carcinoma of the prostate gland with comparable prostate cancer death rates between the LR and favorable IR cohorts. The prostate cancer death rate in unfavorable IR was substantially greater than the most favorable patients but did not reach the magnitude of HR patients. Two hundred and sixteen

Table 3. Univariate and multivariate analysis for predicting failure or brachytherapy patients (only those with a univariate $p$-value of $<0.100$ were included in the multivariate analysis)

\begin{tabular}{|c|c|c|c|c|c|c|c|c|c|c|c|c|}
\hline \multirow[t]{3}{*}{ Variable } & \multicolumn{4}{|c|}{ Cause-specific survival ${ }^{\text {cr }}$} & \multicolumn{4}{|c|}{ Biochemical failure ${ }^{c r}$} & \multicolumn{4}{|c|}{ Overall mortalitycx } \\
\hline & \multicolumn{2}{|c|}{ Univariate } & \multicolumn{2}{|c|}{ Multivariate } & \multicolumn{2}{|c|}{ Univariate } & \multicolumn{2}{|c|}{ Multivariate } & \multicolumn{2}{|c|}{ Univariate } & \multicolumn{2}{|c|}{ Multivariate } \\
\hline & $p$ & SHR & $p$ & SHR & $p$ & SHR & $p$ & SHR & $p$ & $\mathrm{HR}$ & $p$ & $\mathrm{HR}$ \\
\hline Risk & $<0.001$ & & & & $<0.001$ & & & & $<0.001$ & & 0.342 & \\
\hline Unfavorable IR vs. low & 0.042 & 0.205 & 0.256 & & $<0.001$ & 0.194 & $<0.001$ & 0.224 & 0.002 & 0.737 & & \\
\hline $\begin{array}{l}\text { Unfavorable IR vs. favor- } \\
\text { able IR }\end{array}$ & 0.126 & & 0.324 & & 0.001 & 0.303 & 0.020 & 0.408 & 0.193 & & & \\
\hline Unfavorable IR vs. high & 0.011 & 2.975 & 0.010 & 3.562 & 0.006 & 1.760 & 0.001 & 2.317 & 0.095 & & & \\
\hline Age $^{c}$ & 0.791 & & & & 0.986 & & & & $<0.001$ & 1.091 & $<0.001$ & 1.093 \\
\hline Pre-implant PSAC & $<0.001$ & 1.049 & 0.794 & & $<0.001$ & 1.050 & 0.003 & 1.029 & 0.058 & & 0.854 & \\
\hline$\%$ positive biopsies ${ }^{c}$ & $<0.001$ & 1.032 & 0.001 & 1.023 & $<0.001$ & 1.025 & $<0.001$ & 1.017 & $<0.001$ & 1.006 & 0.009 & 1.004 \\
\hline Body mass index ${ }^{c}$ & 0.266 & & & & 0.775 & & & & 0.091 & & 0.433 & \\
\hline Prostate volume & 0.040 & 1.038 & $<0.001$ & 1.068 & 0.055 & & $<0.001$ & 1.041 & 0.921 & & & \\
\hline$\% D_{90}{ }^{c}$ & 0.658 & & & & 0.485 & & & & 0.373 & & & \\
\hline XRT (yes or no) & 0.008 & 3.807 & 0.788 & & $<0.001$ & 2.511 & 0.174 & & 0.017 & 1.207 & 0.462 & \\
\hline ADT (yes or no) & 0.190 & & & & 0.935 & & & & 0.067 & & 0.988 & \\
\hline ADT duration & 0.030 & & 0.839 & & 0.011 & & & & 0.054 & & & \\
\hline O vs. $\leq 6$ months & 0.878 & & & & 0.084 & & 0.028 & 0.510 & - & & 0.625 & \\
\hline 0 vs. $>6$ months & 0.013 & 3.023 & & & 0.039 & 1.608 & 0.004 & 0.434 & - & & 0.434 & \\
\hline Tobacco & 0.078 & & 0.069 & & 0.304 & & & & $<0.001$ & & $<0.001$ & \\
\hline Never vs. former & & & & & & & & & $<0.001$ & 1.478 & 0.002 & 1.335 \\
\hline Never vs. current & & & & & & & & & $<0.001$ & 2.152 & $<0.001$ & 2.624 \\
\hline Testosteronet: & $<0.001$ & & & & 0.372 & & & & 0.478 & & & \\
\hline $\begin{array}{l}\text { Low \& low norm vs. } \\
\text { mid norm }\end{array}$ & 0.321 & & & & & & & & - & & & \\
\hline $\begin{array}{l}\text { Low \& low norm vs. } \\
\text { high \& high norm }\end{array}$ & $<0.001$ & * & & & & & & & - & & & \\
\hline Hypertension (yes or no) & & & & & & & & & 0.003 & 1.260 & 0.154 & \\
\hline Diabetes (yes or no) & & & & & & & & & $<0.001$ & 1.633 & 0.001 & 1.438 \\
\hline $\begin{array}{l}\text { Coronary artery disease } \\
\text { (yes or no) }\end{array}$ & & & & & & & & & $<0.001$ & 1.812 & $<0.001$ & 1.472 \\
\hline $\begin{array}{l}\text { Hypercholesterolemia } \\
\text { (yes or no) }\end{array}$ & & & & & & & & & 0.517 & & & \\
\hline
\end{tabular}

${ }^{*}$ Approaching negative or positive infinity

${ }^{t}$ Only 1693 patients had testosterone values, therefore, testosterone was not included in the cause-specific multivariate analysis

continuous data

${ }^{c r}$ Competing risk analysis

cxForward conditional Cox proportional hazards model 
patients (32.9\% of all deaths) died of second malignancies with lung cancer being the most likely secondary cause of cancer death.

In multivariate analysis (Table 3), BF was best predicted by risk group, pre-implant PSA, percent positive biopsies, smaller prostate volume, and ADT duration. Prostate cancer specific mortality was most closely related to risk group, percent positive biopsies, and prostate volume. Overall mortality was best predicted by age, percent positive biopsies, tobacco consumption, diabetes mellitus, and coronary artery disease.

\section{Discussion}

Biochemical control rates following local therapy for IR prostate cancer remain variable with multiple brachytherapy series demonstrating superior biochemical control rates when compared to EBRT or radical prostatectomy $[1,11,12,17,18,19]$. However, within each modality, differences in outcome between favorable and unfavorable IR patients suggest that the Zumteg and Spratt IR risk group stratification successfully identifies patients with differing prognosis, which may allow for a more tailored treatment approach.

The results of our study indicate that brachytherapy is highly efficacious for patients of all risk groups. Favorable IR patients have biochemical control rates comparable to those of LR patients ( $1.4 \%$ vs. $2.2 \%$ BF at 15 years, Figure 1). Unfavorable IR patients had more than a 3-fold increased risk of BF and PCSM (Figures 1 and 2) compared to favorable IR patients. However, unfavorable IR patients do have a better prognosis than HR patients. What remains unclear is whether further intensification of treatment with more prolonged ADT and/or more extensive (dose and/or volume) EBRT would further improve the outcome of the unfavorable IR cohort.

However, what is clear is that the absolute difference in BF among favorable and unfavorable IR brachytherapy patients is substantially less than that reported for other modalities. Zumteg et al. reported 8 year biochemical failure rates of $13.9 \%$ and $28.9 \%$ for favorable and unfavorable IR cohorts following IMRT [8]. Following radical prostatectomy, Yung et al. reported 5 year biochemical failure rates of $12.5 \%$ and $33.5 \%$ for favorable and unfavorable IR cohorts [10]. In addition, in terms of prostate cancer specific death, Keane and colleagues in a prospective randomized trial of IR patients treated with EBRT with or without ADT reported no prostate cancer deaths at 15 years in men with favorable IR but a $13.1 \%$ death rate in unfavorable IR patients [9]. In our study, we report a $0.6 \%$ rate of prostate cancer deaths at 15 years in men with favorable IR disease but only a $2.2 \%$ risk of PCSM at 15 years in unfavorable IR patients [2]. Overall mortality is closely associated with tobacco use, coronary artery disease, and diabetes mellitus. All 3 of these parameters are amendable to changes in lifestyle and/or intensive medical management. Because of low rates of prostate cancer death at 15 years, future directions should focus on whole body care with implementation of wellness programs.

Shortcomings of our study include that all patients were treated at a single institution by a single brachyther- apist. In addition, the decision to use supplemental EBRT (including dose and treated volume) and ADT was not controlled, and may have influenced our outcomes. Strengths of our study included that all patients were treated with a consistent implant philosophy with documented dose escalation (mean day $0 \mathrm{D}_{90} 121.5 \%$ of prescription dose).

\section{Conclusions}

Patients with favorable IR disease have biochemical and PCSM outcomes comparable to those of patients with LR disease. Although unfavorable IR has greater than a 3-fold increased risk of BF and PCSM when compared to favorable IR, the outcomes remain superior to those men with HR disease.

\section{Disclosure}

Authors report no conflict of interest.

\section{References}

1. Taira AV, Merrick GS, Butler WM et al. Time to failure after definitive therapy for prostate cancer: implications for importance of aggressive local treatment. J Contemp Brachytherapy 2013; 5: 215-221.

2. Mohler J, Bahnson RR, Boston B et al. NCCN clinical practice guidelines in oncology: prostate cancer. J Natl Compr Canc Netw 2010; 8: 162-200.

3. Partin AW, Mangold LA, Lamm DM et al. Contemporary update of prostate cancer staging nomograms (Partin Tables) for the new millennium. Urology 2001; 58: 843-848.

4. Nguyen PL, Chen MH, Catalona WJ et al. Predicting prostate cancer mortality among men with intermediate to high-risk disease and multiple unfavorable risk factors. Int J Radiat Oncol Biol Phys 2009; 73: 659-664.

5. Bittner N, Merrick GS, Galbreath RW et al. Greater biopsy core number is associated with improved biochemical control in patients treated with permanent prostate brachytherapy. Int J Radiat Oncol Biol Phys 2010; 78: 1104-1110.

6. Bian SX, Kuban DA, Levy LB et al. Addition of short-term androgen deprivation therapy to dose-escalated radiation therapy improves failure-free survival for select men with intermediate-risk prostate cancer. Ann Oncol 2012; 23: 2346-2352.

7. Merrick GS, Butler WM, Galbrath RW et al. Relationship between percent positive biopsies and biochemical outcome after permanent interstitial brachytherapy for clinically organ-confined carcinoma of the prostate gland. Int J Radiat Oncol Biol Phys 2002; 52: 664-673.

8. Zumsteg ZS, Spratt DE, Pei I et al. A new risk classification system for therapeutic decision making with intermediate-risk prostate cancer patients undergoing dose-escalated external-beam radiation therapy. Eur Urol 2013; 64: 895-902.

9. Keane FK, Chen MH, Zhang D et al. The likelihood of death from prostate cancer in men with favorable and unfavorable intermediate-risk disease. Cancer 2014; 120: 1787-1793.

10. Jung JW, Lee JK, Hong SK et al. Stratification of patients with intermediate-risk prostate cancer. BJU Int 2015; 115: 907-912.

11. Merrick GS, Wallner KE, Galbreath RW et al. Is supplemental external beam radiation therapy necessary for patients with higher risk prostate cancer treated with 103Pd? Results of two prospective randomized trials. Brachytherapy 2015; 14: 677-685.

12. Merrick GS, Wallner KE, Galbreath RW et al. Is supplemental external beam radiation therapy essential to maximize 
brachytherapy outcomes in patients with unfavorable intermediate-risk disease? Brachytherapy 2015; doi: 10.1016/j. brachy.2015.09.011 [in press].

13. Merrick GS, Butler WM. Modified uniform seed loading for prostate brachytherapy: rationale, design, and evaluation. Tech Urol 2000; 6: 78-84.

14. Merrick GS, Butler WM, Wallner KE et al. Extracapsular radiation dose distribution after permanent prostate brachytherapy. Am J Clin Oncol 2003; 26: e178-189.

15. Alexander J, Weinberg V, Gottschalk AR et al. Pre-plan parameters predict post-implant D90 $\geq 140$ Gy for (125)I permanent prostate implants. J Contemp Brachytherapy 2014; 6: 143-153.

16. Kuban DA, Levy LB, Potters L et al. Comparison of biochemical failure definitions for permanent prostate brachytherapy. Int J Radiat Oncol Biol Phys 2006; 65: 1487-1493.

17. Stone NN, Stock RG, Cesaretti JA et al. Local control following permanent prostate brachytherapy: effect of high biologically effective dose on biopsy results and oncologic outcomes. Int J Radiat Oncol Biol Phys 2010; 76: 355-360.

18. Spratt DE, Zumsteg ZS, Ghadjar P et al. Comparison of highdose (86.4Gy) IMRT vs. combined brachytherapy plus IMRT for intermediate-risk prostate cancer. BJUI 2014; 114: 360-367.

19. Zelefsky MS, Chou PF, Pei X et al. Predicting biochemical tumor control after brachytherapy for clinically localized prostate cancer: The Memorial Sloan-Kettering Cancer Center experience. Brachytherapy 2012; 11: 245-249. 